\title{
Letters
}

\section{Trainees' attitudes to shift work depend on grade and specialty}

Editor-How doctors in training view the changes in their working pattern that will be required by the European working time directive is not known. ${ }^{1}$ By 2004 it will limit their continuous working to no more than 13 hours in 24. As work has been defined as being at the workplace on duty, even if sleeping, this will mean shift work for those who must be resident when on call.

Some British doctors in training have indicated that they are opposed to any reduction in working hours because of the impact on the experience or the education they would acquire. ${ }^{2}$ Others have been opposed to the idea of shift work because of the impact on their personal or social lives. ${ }^{3}$ We explored whether such views were general.

We used methods previously reported to conduct a survey of trainees at all grades and in all specialties in NHS trusts in south London. ${ }^{4}$ We asked: "Would you like a working pattern of 56 hours or less in shifts of no more than 13 hours?" Those who answered "no" were asked to give the main reason why not. We received 1548 responses out of a possible 2100 , a response rate of $73.7 \%$. Of the respondents $51.8 \%$ were men $(803 / 1548)$.

Negative attitudes to shift working increased with seniority (table). No significant difference was found between the responses of men and women in each grade. The figure shows the responses of senior house officers and specialist registrars intending a career in the different specialties. Only intended psychiatrists and surgeons were mainly opposed to shift working.

The main reason given for opposing shift work among surgeons was the likely impact on experience $(63 \%, 87 / 138)$, followed by the likely impact on social/ family life $(25 \%, 35 / 138)$. For other trainees the likely impact on social or family life was the response chosen most often $(46 \%$, 193/417), and the likely impact on

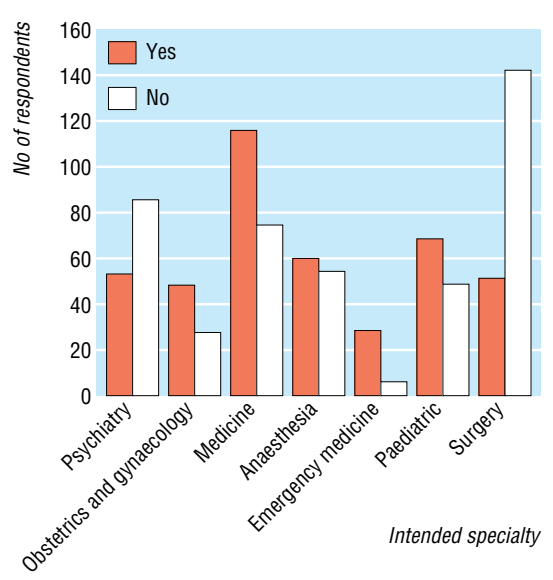

Senior house officers' and specialist registrars' preference for working 13 hour shifts in 56 hour week by intended specialty

experience was less important (21\%, 86/417).

The anxieties of senior trainees about the impact on social or family life and the anxieties of surgeons in training about the impact of shift work on their experience must be taken seriously. Whenever practicable, senior trainees should be allowed to be on call from home, reducing the need for shift working.

Maryanne Aitken project officer

maitken@londondeanery.ac.uk

Elisabeth Paice dean

London Postgraduate Medical and Dental

Education, London WC1N 1DZ

1 Pickersgill T. The European working time directive for doctors in training. $B M J$ 2001:323:1266.

2 Alkhulaifi A, Allen SM, Anderson JR, Argano V, Austin C Barlow C, et al. New deal not satisfactory for cardiothoracic surgery. BMJ 1995;311:953.

3 Mather H, Royal College of Physicians Trainees Committee. The Royal College of Physicians specialist registrar shift survey. Hospital Med 2002;63:429-31.

4 Paice E, Aitken M, Cowan G, Heard S. Trainee satisfaction before and after the Calman reforms of specialist training: questionnaire survey. BMJ 2000;320:832-6.

Answers to question: "Would you like a working pattern of 56 hours or less in shifts of no more than 13 hours" by grade. Values are numbers (percentages) of doctors

\begin{tabular}{lccc} 
Grade & Yes & No & Don't know \\
\hline Preregistration house officer $(\mathrm{n}=229)$ & $125(54.6)$ & $46(20.1)$ & $58(25.3)$ \\
\hline Senior house officer $(\mathrm{n}=689)$ & $353(51.2)$ & $229(33.2)$ & $107(15.5)$ \\
\hline Specialist registrar $(\mathrm{n}=630)$ & $232(36.8)$ & $315(50.0)$ & $83(13.2)$ \\
\hline Total $(\mathrm{n}=1548)$ & $710(45.9)$ & $590(38.1)$ & $248(16.0)$ \\
\hline
\end{tabular}

Pearson $\chi^{2}=82.198, d f=4 ; P<0.001$.

\section{Delayed discharge and hospital congestion}

\author{
One nettle to be grasped is discharging \\ patients against their or their families' \\ wishes...
}

EDIToR-Black and Pearson identified the complex factors driving up length of stay and causing palpable tensions in every hospital in the United Kingdom. ${ }^{1}$ The NHS is unique among health services in having no effective lever to discharge patients who no longer require hospital care. Black and Pearson say that patients can elect to remain in hospital until a final placement is found. In reality it is not so much patients seeking placements at rest homes and nursing homes but their families, who have the power to adopt an approach of masterful inactivity to discharge.

In North America and most of Europe powerful financial incentives mitigate unnecessary delays to discharge from hospital. We have the ludicrous situation whereby many frail acutely ill elderly people are being discharged home too early in an attempt to reduce their length of stay by one or two days, with all the concomitant risks of failed discharge and readmission. At the other end of the spectrum many discharges grind to a halt, with inordinately long length of stay far outweighing the occupied bed days saved by risky premature discharge. We are compromising the care of acutely ill elderly people at the expense of neglecting the delayed discharges of a relatively small number of patients with very long length of stay.

In our own unit a spot survey in October last year showed that out of 398 beds in the department, 152 were occupied by patients whose discharge had been delayed. Of the 172 patients in continuing care, four were deemed to have had their discharge delayed owing to patient or family choice. These patients had an average delay of about 210 days from the time they were deemed fit for dischargethe equivalent of lopping two days off the length of stay of 100 acute patients.

We need to tackle the politically sensitive issue of discharging patients from hospital against patients', or more realistically patients' families', wishes rather than invest huge effort in trying to prevent admission of acutely ill patients with a variety of ill conceived and untested initiatives for intermediate care. We suspect that this will not happen so long as politicians and policy makers fear the adverse publicity from a few 
individual cases more than the less dramatic media coverage of delayed discharges and cancelled operations.

David R J Jarrett consultant geriatrician DavidDr.Jarrett@porthosp.nhs.uk

Anna Hinton specialist registrar

Department of Medicine for Elderly People, Queen Alexandra Hospital, Portsmouth P06 3LY

1 Black D, Pearson M. Average length of stay, delayed discharge, and hospital congestion. BMJ 2002;325;610-1. (21 September.)

\section{$\ldots$ and another is primary care occurring} in hospitals

EDITOR-Black and Pearson draw attention to the issues that lie behind congestion of hospitals. ${ }^{1}$ But there is a nettle to be grasped here. Are more patients being inappropriately referred and admitted to hospital? I think the answer to this has to be yes, although the reasons are complex.

The current government has encouraged the population of the United Kingdom to consider other methods of accessing health care than through general practitioners (NHS Direct, pharmacists, walk in centres). However, hospital assessment is now seen as a "must have" by the patients and their general practitioners, whether it be in an emergency department or a medical admissions unit.

Yet a large proportion of such patients have self limiting illnesses that might in the past have been looked after by their general practitioners. In hospitals, such as ours, where it is now possible for referral to be made by fax, a notable proportion of what is seen on a medical admissions unit is primary care taking place in the secondary care sector. I see no sign of primary care trusts addressing this issue.

David J Seddon consultant, health care of the elderly Queen's Medical Centre, Nottingham NG7 1AE djseddon@btinternet.com

1 Black D, Pearson M. Average length of stay, delayed discharge, and hospital congestion. BMJ 2002;325;610-1. (21 September.)

\section{Emergency pyramid is inverting already}

EDITOR-Turner and Collinson suggestion that it is time to invert the knowledge pyramid in accident and emergency medicine. ${ }^{1}$ Triage was shown to be effective many years ago, when $30 \%$ of patients needed no further care in an emergency department. $^{2}$

Since then it has been shown that creating a one stop system for patients with minor injuries is also effective in reducing waits. ${ }^{3}$ Further redesign of having senior staff as the first clinical contact rather than a triage and wait approach is now being used in several emergency departments and is successfully reducing waits. ${ }^{45}$

For this reason, the NHS Modernisation Agency's emergency services collaborative is hosting a series of national workshops focusing on this new principle of "see and treat" and, with the support of the British Associ- ation for Accident and Emergency Medicine and the Royal College of Nursing, will be issuing guidance on establishing such systems. Every emergency department in England was invited to these workshops in November last year.

The principles of "see and treat" draw on the learning of the primary care collaborative that pioneered the concept of advanced access in England. In primary care advanced access is concerned with seeing today's patients today. In emergency care this can be translated to mean seeing this minute's patients this minute. Interestingly, in primary care no increase in activity was noted despite concerns that this might have occurred.

Turner and Collinson also suggest ways of dissuading people with non-emergency problems from attending emergency departments. This resurrects the faded idea of inappropriate attendance that in emergency care has long since been replaced by the concept of an inappropriate NHS response, thus taking the blame away from patients and instead thinking how the service can best meet their needs.

It is perhaps unfair to expect users to know and understand the intricacies of the NHS's complex emergency care system, when the average person visits an emergency department only once every five years and calls an ambulance every 17 years (and for a different condition each time). A more positive approach would be to modernise and improve integration of emergency services to meet patients' needs.

Many staff in emergency departments are working hard to develop local partnership arrangements with primary care, ambulance services, dental services, walk-in centres, minor injury units, local pharmacies, NHS Direct, and others to demystify service provision and improve access for the benefit of patients. The further development of local emergency care networks is also aimed at supporting these changes.

Matthew Cooke national clinical lead, emergency care performance improvement

m.w.cooke@warwick.ac.uk

Karen Castille director of emergency care

NHS Modernisation Agency, London SW1A 2NS

1 Turner S, Collinson T. When is an emergency department not an emergency department? BMJ 2002;325:901. (19 October $)$

2 Redmond $\mathrm{AD}$, Buxton N. Consultant triage of minor cases in an accident and emergency department. Arch Emerg Med 1993;10:328-30.

3 Cooke MW, Wilson S, Pearson S. The effect of a separate stream for minor injuries on accident and emergency department waiting times. Emerg Med J 2002;19:28-30.

4 NHS Modernisation Agency. Improvement in emergency care: case studies. October 2002 www.modern.nhs.uk/esc 8237/Case $\% 20$ Studies $\% 20 \% 20$ Low $\% 20$ Res $\% 20$.pd (accessed 10 Dec 2002).

5 Dancocks A. Improving waiting times. EMJ Online 2002;8 January http://emjbmijournalscom/coi/eletters/19/1/ $28 \# 37$ (accessed 20 Oct 2002)

\section{Managing acute appendicitis}

Technology at expense of clinical evaluation will diminish quality of care

EDITOR-Like many others will have been, I was astonished at the assertion in Benjamin and Patel's leader that mortality from negative appendicectomy $(1.5 \%)$ exceeded that of appendicectomy for acute appendicitis $(0.2 \%){ }^{1}{ }^{1}$ It is clear from reading their source document, that this is a seriously misleading statistic, the figure of $1.5 \%$ representing the mortality of comorbidity rather than that of the appendicectomy itself. ${ }^{2}$

In a study of all 805 deaths from appendicitis or appendicectomy in Scotland (population 5 million) over 10 years to 1963, mortality from appendicectomy for appendicitis was $0.62 \%$, and that from negative appendicectomy was $0.06 \%$. Seventy one of the 605 patients $(11.7 \%)$ for whom clinical records could be studied had previously been treated non-operatively for suspected appendicitis, and 55 of them died from gangrenous or perforated appendicitis. ${ }^{3}$ For patients aged 12-29, in whom diagnostic difficulty is greatest, mortality from appendicectomy for appendicitis and for negative appendicectomy was $0.16 \%$ and $0.02 \%$; the death rate from missed appendicitis-difficult to calculate exactlywas at least $0.04 \%$.

Attempting to project these results to the then competing management strategies I described as conservative (operating on around $60 \%$ of patients admitted with possible appendicitis) and radical (operating on $80 \%$ of such admissions) for patients in the age group $12-29,{ }^{4}$ I estimated that avoidable mortality (death from missed appendicitis plus that from negative appendicectomy) from the two approaches was virtually identical at 1.13 and 1.07 patients per 10000 admissions-figures which then represented 0.6 avoidable deaths per year in Scotland. It is hard to believe that all the advances described by Benjamin and Patel since then can have done all that much to improve these statistics.

Two other observations are relevant.

Firstly, appendicectomy but not appendicitis runs in families.

Secondly, conservative surgeons become radical surgeons when dealing with medical and nursing colleagues and their families when they present with possible appendicitis. In this field at least, surgerylike general practice-combines the skills of a behavioural with those of a biomedical science.

Jones ends his review of the contemporary management of suspected acute appendicitis by saying that we can be sure that emphasis on technology at the expense of clinical evaluation will diminish, rather than improve, the quality of care for patients with acute abdominal pain-a truth that surely has much wider applications. ${ }^{5}$

John Howie emeritus professor, general practice

4 Ravelrig Park, Balerno EH14 7DI

john.howie@btopenworld.com

1 Benjamin IS, Patel AG. Managing acute appendicitis. BMJ 2002;325:505-6. (7 September.)

2 Flum DR, Koepsell T. The clinical and economic correlates of misdiagnosed appendicitis: nationwide analysis. Arch Surg 2002;137:799-804.

3 Howie JGR. Death from appendicitis and appendicectomy. Lancet 1966;ii:1344-7. 
4 Howie JGR. The place of appendicectomy in the treatment of young adults with possible appendicitis. Lancet 1968;ii:1365-7.

5 Jones PF. Suspected acute appendicitis: trends in management over 30 years. BrJ Surg 2001;88:1570-7.

\section{Neuroimmune appendicitis may be distinct pathological entity}

EDITOR-Benjamin and Patel discussed the management of acute appendicitis. ${ }^{1}$ In clinical practice every surgeon would like to avoid unnecessary appendicectomies, and removal of a histologically normal appendix in patients with suspected acute appendicitis has always been a matter of concern.

The authors say that negative appendicectomy has a rate as high as $20 \%$. A histologically normal appendix does not always mean a normal appendix. Some histologically normal appendixes in patients with acute pain in the right iliac fossa contain abnormal concentrations of neuropeptides, which may explain the relief of pain after removal of a histologically normal appendix. $^{23}$ The abnormal content of neuropeptides and the observed neuronal sprouting, possibly combined with the immunological response, could be part of the pathogenesis of pain in patients with a clinical diagnosis of acute appendicitis and a histologically normal appendix..$^{3-5}$

These data, together with increasing knowledge about the way in which the nervous system and immune cells can interact, imply that neuroimmune appendicitis is a distinct pathological entity. ${ }^{2}$

Rajesh K Choudhary staff grade surgeon choudhary@lineone.net

A M F Hassn consultant surgeon

Department of Surgery, General Hospital,

Bishop Auckland, County Durham DL14 6AD

1 Benjamin IS, Patel AG. Managing acute appendicitis. BMJ 2002;325:505-6. (7 September.)

2 DiSebastiano P, Fink T, diMola FF, Weihe E, Buchler MW Neuroimmune appendicitis. Lancet 1999;354:461-6.

3 Wang Y, Reen DJ, Puri P. Is a histologically normal appenWang Y, Reen DJ, Puri P. Is a histologically normal appen-
dix following emergency appendicectomy always normal?

Lancet 1996; 347:1076-79.
4 Stead RH,Franks AJ, Goldsmith CH, Bienenstock J, Dixon 4 Stead RH, Franks AJ, Goldsmith CH, Bienenstock J, Dixon
MF. Mast cells, nerves and fibrosis in the appendix: a morMF. Mast cells, nerves and fibrosis in the appendix:
phological assessment. J Pathol 1990;161:209-19.

5 Olsen BS, Holck S. Neurogenous hyperplasia leading to appendiceal obliteration: an immunohistological study of 237 cases. Histopathy 1987;11:843-49.

\section{Preventing and treating eclamptic seizures}

\section{Will magnesium sulphate for pre-eclampsia really help?}

EDITOR-I agree with Roberts et al that the evidence from the eclampsia trial published in 1995 justifies the use of magnesium sulphate for eclampsia. ${ }^{12}$ However, I am not yet convinced by the results of the Magpie study ${ }^{3}$ that treating all patients with severe pre-eclampsia will have a clinically significant benefit in the setting in which I work.

We have a very busy unit and are critically understaffed, a situation that is probably the norm in many developing countries. We often admit several patients with severe pre-eclampsia a day. Giving magnesium sulphate to all of them would create an increased workload for our unit (administration of magnesium sulphate, monitoring of intravenous infusion if that route is chosen, monitoring of respiratory rates, reflexes, urine output), which might detract from the care we offer other patients.

According to the Magpie study, for every 60 women we treat, we would prevent one case of eclampsia. ${ }^{3}$ Would the prevention of this one case be important? We keep all patients with severe pre-eclampsia in hospital. If one has an eclamptic seizure, we manage it appropriately with magnesium sulphate and delivery, and we expect a good outcome for the mother. The women who die or develop severe morbidity from eclampsia in our setting are usually those who have had multiple seizures before they reach hospital. Thus the number we would need to treat to prevent one death or one case of severe morbidity would be many more than 60 .

The critical issues in the management of patients with severe pre-eclampsia are appropriate monitoring for complications and appropriate timing of delivery. If these aspects are managed well, I doubt that magnesium sulphate will have a clinically significant impact on the outcome in these patients.

Neil F Moran consultant obstetrician

Mahatma Gandhi Memorial Hospital, Private bag X13, Mount Edgecombe, KwaZulu-Natal 4300, South Africa

973195674@nu.ac.za

1 Roberts JM, Villar J, Arulkumaran S. Preventing and treatin eclamptic seizures. BMJ 2002;325:609-10. (21 September.) 2 Eclampsia Trial Collaborative Group. Which anticonvulsant for women with eclampsia? Evidence from the collaborative eclampsia trial. Lancet 1995;345:1455-63.

3 The Magpie Trial Collaboration Group. Do pre-ection pre-eclampsia, and their babies, benefit from magnesium sulphate? The Magpie trial: a randomi

\section{Other causes of death need to be treated}

EDITOR-The editorial by Roberts et al on the favourable effect of magnesium sulphate on recurrent eclamptic seizures and prophylaxis of eclampsia in developing countries is encouraging. ${ }^{1}$ However, a study of recent maternal mortality at Hospitali Teule, Muheza, Tanzania, indicates that it will have only a modest effect overall at this hospital (table).

Eclampsia accounts for only $5.3 \%$ of the grand total, or $7.6 \%$ if cases of hypertension

Numbers of maternal deaths by primary cause among 12133 deliveries at Hospitali Teule, Muheza, Tanzania, 1997-2001

\begin{tabular}{lc|lc}
\multicolumn{1}{c|}{ Direct $\mathbf{( n = 8 7 )}$} & \multicolumn{2}{c}{ Indirect $\mathbf{( n = 8 3 )}$} & 33 \\
\hline Eclampsia & 9 & Malaria & 6 \\
\hline Hypertension & 4 & Anaemia & 5 \\
\hline Haemorrhage & 25 & Tuberculosis & 4 \\
\hline Sepsis & 21 & Meningitis & 11 \\
\hline Abortion & 16 & Infection & 8 \\
\hline Ectopic pregnancy & 6 & HIV & 6 \\
\hline Ruptured uterus & 6 & Pneumonia & 4 \\
\hline & & Heart disease & 6 \\
\hline
\end{tabular}

are included. Thus the task of reducing Muheza's maternal death toll probably depends more on other factors, particularly malaria prophylaxis; effective measures to reduce infection, anaemia, and HIV; and a reliable blood bank and better transport facilities.

Ben Moore visiting obstetrician

15 St Margaret's Road, Hereford HR1 1TS benveronicamoore@aol.com

Richard Collins chief medical officer

Hospitali Teule, Muheza, Tanga Province, Tanzania

1 Roberts JM, Vilar J, Arulkumaran S. Preventing and treating eclamptic seizures. BMJ 2002;325:609-10. (21 September.)

\section{Alcohol handrubs $v$ soap}

\section{Finnish experience shows that alcohol rubs are good for hands}

EDITOR-Girou et al compared the use of alcohol based handrubs with standard used in Finland since the 1980s, and hand hygiene in health care.

Healthcare workers have accepted the method, and complaints of dry skin are fewer than with using other hand hygiene products. ${ }^{23}$ Alcoholic preparations must of course contain skin emollients such as $1-2 \%$ glycerol to prevent drying of the skin.

Juhani Ojajarvi senior medical officer

National Agency for Medicines, Medical Devices

Centre, PO Box 55, F-00301 Helsinki, Finland

juhani.ojajarvi@nam.fi

1 Girou E, Loyeau S, Legrand P, Oppein F, Brun-Boisson C. Efficacy of handrubbing with alcohol based solution versus standard handwashing with antiseptic soap: randomised clinical trial. BMJ 2002;325:362. (17 August.)

2 Ojajärvi J, Mäkelä P, Rantasalo I. Failure of hand disinfection with frequent hand washing: a need for profield studies. J Hyg 1977;79:107-19.

3 Ojajärvi J. Handwashing in Finland. J Hosp Infect 1991;18(suppl B):35-40.

\section{Alcohol handrub removes methicillin resistant Staphylococcus aureus}

EDITOR-Girou et al showed that handrubbing with an alcohol based solution is significantly more efficient than handwashing with antiseptic soap in reducing hand contamination during routine patient care. $^{1}$ We conducted a similar study of the efficacy of an alcohol handrub $(70 \%$ ethanol, carbomer, isopropyl myristate, glycerine, monopropylene glycol, vitamin E, and demineralised water; Guest Medical, handwashing. ${ }^{1}$ Such handrubs have been handrubbing is the preferred choice for 
Kent, UK) in eliminating methicillin resistant Staphylococcus aureus from the fingertips of hospital staff at work.

The study was conducted in a large district general hospital in north London in December 2001. Altogether, 110 healthcare staff including doctors, nurses, occupational therapists, healthcare support workers, administrators, and porters were approached at random in their area of work on a single day and invited to take part anonymously. There was no prior knowledge of the study. Each member of staff was asked to place prints of their dominant thumb, index finger, and middle finger onto a plate of Baird Parker agar (selective for $S$ aureus). Two squirts (around $0.5 \mathrm{ml}$ in total) from a $50 \mathrm{ml}$ pocket size dispenser of the alcohol handrub were then sprayed onto their hands, and they were asked to apply this as they would normally-with no extra instruction. After the alcohol was allowed to dry fully, fingerprints were taken again in the same way onto a fresh agar plate. Plates were incubated at $37^{\circ} \mathrm{C}$ for 48 hours.

Typical colonies were confirmed as $S$ aureus and checked for methicillin sensitivity in the normal way. We found that before using the handrub 25 of the 110 staff formed one or more colony forming units of methicillin resistant $S$ aureus from their fingerprints. Most grades of staff had some positive results, although most of the positive results were from those working in two or three specific areas in the hospital. After using handrub only three members of staff grew colonies from their fingerprints.

This illustrates the efficacy of an alcohol handrub in reducing hand contamination with methicillin resistant $S$ aureus at work. We plan to repeat the exercise every quarter both as surveillance and as a useful practical educational tool for staff.

Arti Thakerar fourth year medical student Barts and the Royal London Hospitals and School of Medicine, London E1 2AD arti_thakerar@doctorsworld.com

Collin Goodbourn consultant microbiologist Whipps Cross University Hospital NHS Trust, London E11 1NR

1 Girou E, Loyeau S, Legrand P, Oppein F, Brun-Boisson C. Efficacy of handrubbing with alcohol based solution versus standard handwashing with antiseptic soap: randomised clinical trial. BMJ 2002;325:362. (17 August.)

\section{Outdated drugs may be useful}

EDITOR-The personal view by WoolrichBurt about her work in Nepal highlighted many of the problems of trying to provide healthcare in poor countries. ${ }^{1}$ Examples include the inappropriate medicines that may be donated and freighted out at considerable cost, the precious money wasted on multiple consultations, and the belief that the more medicines swallowed the more effective the cure.

I disagree with just one of her pointsthat outdated drugs should be thrown away. Often in situations pertaining to developing countries, the alternative to outdated medicine is no medicine at all. When we had more surgery to do than we had anticipated I have used lignocaine at least 10 years out of date, stored away in a hospital pharmacy in the middle of the country, without any apparent loss of its effect. I have found that even biologically active drugs such as freeze dried hyaluronidase seem to retain their potency even years after an expiry date. When unable to sleep because of jet lag, I have benefited from very outdated temazepam.

This issue of drugs - or even of sterile wrapped equipment, such as intraocular lenses-that are past their expiry date is unfortunately an extremely sensitive one with customs officials and the like in developing countries. I understand the point of view of someone without any scientific training who sees a label stating that something has expired on a certain date and feels it is his or her responsibility to destroy or confiscate it to protect the country from the condescending benevolence of the rich Western world.

The reality is that medicines do not expire: patients expire. Medicines, like old soldiers, just fade away, usually very, very slowly. It would be much better for al concerned if medicines were instead labelled in a manner such as "after $\mathrm{xxx}$ [date] this drug can no longer be guaranteed to be $100 \%$ effective, especially if it has been stored in hot or very light conditions."

John Sandford-Smith emeritus consultant ophthalmologist

Leicester LF9 $2 \mathrm{PE}$

jsandfordsmith@compuserve.com

1 Woolrich-Burt L. First do no harm: does the Hippocratic oath extend to developing countries? BMI 2002;325:783. (5 October.)

\section{Sustaining medical education is difficult in poor countries}

Editor-Broadhead and Muula describe the problems and achievements in creating a medical school for Malawi from scratch. The hailed success in its first 20 years since inception mirrors most medical schools in sub-Saharan Africa. The bigger challenge is sustaining the future of the school. The reasons for failure of most medical schools in sub-Saharan Africa must now be studied. The failings of institutions in resource rich countries must also be assessed while appreciating ongoing success.

Case by case analysis of medical schools in sub-Saharan Africa would show an excellent first 10 years followed by a general downward spiral. History over the past 45 years clearly shows this pattern throughout Africa. The current international reputations of the schools are not similar to those during their first 10 years, although esteem for South African institutions remains much higher.

The reasons are complex. Few are inherent to the medical school, most resulting from external forces beyond their control. These include civil wars, civil strife, political instability, lack of appreciation of local talent and advice, diminishing health budgets in real terms, and economic misdirection.
It has not been easy in neighbouring Zambia for its only medical school, which is 34 years old. Although the school is in one of the most peaceful countries on earth, it is subject to the vagaries of the national economy. Multiple collaborations with institutions abroad seem, however, to be slowly rekindling some lost reputation.

Malawi medical school must develop a firm foundation that will not crumble when external aid dwindles. In a resource poor setting the delivery of medical education is more challenging. ${ }^{2}$ The medical school's successful first 10 years should not be naively accepted but used to make sure that history does not repeat itself.

Joseph Yikona staff physician, elderly services Gosport War Memorial Hospital, Gosport PO12 3PW

joyikona@aol.com

1 Broadhead RL, Muula AS. Creating a medical school for Malawi: problems and achievements. BMJ 2002;325:384-7. (17 August.)

2 Banda S, Yikona J. Medical education. Lancet 2001;358:423.

\section{Alosetron for irritable bowel syndrome}

\section{Senior vice president of GlaxoSmithKline responds}

EDITOR-As the senior doctor at GlaxoWellcome and GlaxoSmithKline who participated in all of the key meetings that resulted in the withdrawal of Lotronex (alosetron) and the subsequent approval for reintroduction, I feel compelled to reply to both the article and editorial on alosetron. ${ }^{2}$

Moynihan sees a complex web of intrigue where none existed, at least from the viewpoint of GlaxoWellcome and GlaxoSmithKline. ${ }^{1}$ Here are the key elements of the story from our position.

We had a medical disagreement with the Food and Drug Administration about the aetiology of the serious adverse events occurring in patients taking alosetron. In November 2000 we had several meetings with the administration, which led to a meeting on 28 November where we realised we could not come to agreement on certain key matters. Reluctantly, we decided that we had no viable option but to withdraw the drug voluntarily.

Having withdrawn the drug, we had no intention of reintroducing it. But thousands of patients contacted both us and the Food and Drug Administration to emphasise the benefits of the drug. It was these pleas that led GlaxoSmithKline and the Food and Drug Administration to try to find common ground to reintroduce the drug. This culminated in April 2002 in an advisory committee, where a full and transparent review of all available data was undertaken.

Over the past 20 months we have worked with the Food and Drug Administration to find a way forward for this drug that will balance safety concerns and practicality in prescribing with the clear desires of patients to have an effective treatment for irritable bowel syndrome. People who were 
at the advisory committee could not fail to have been moved by testimonies from patients whose lives had been changed by alosetron.

The implication that we were somehow in collusion with the Food and Drug Administration is not true. The pharmaceutical industry is highly regulated, and everyone in industry accepts and respects the Food and Drug Administration's authority.

The articles by Moynihan and Lièvre have clouded the subject of the reintroduction of alosetron by misrepresenting the facts. I hope this helps clarify what happened-at least from our point of view. Also, let's not forget who is the ultimate beneficiary-the patient with irritable bowel syndrome for whom alosetron is an effective treatment.

James B D Palmer senior vice president, new product development

GlaxoSmithKline, 5 Moore Drive, Research

Triangle Park (RTP), NC 27709, USA

jbdp0056@gsk.com

1 Moynihan R. Alosetron: a case study in regulatory capture or a victory for patients' rights? BMJ 2002;325:592-5. (14 September.)

2 Lièvre M. Alosetron for irritable bowel syndrome. BMJ 2002;325:555-6. (14 September.)

Risks of using alosetron are still unknown

EDITOR-The discussions of alosetron for irritable bowel syndrome in the 14 September issue were disappointing because the quantitative estimates of risk are unreliable; those cited seem to have been based on reports of events for which causality has not been established. ${ }^{12}$

Lièvre cites an incidence for severe constipation of one in 1000 patients treated for six months and extrapolates to say that if 2 million patients received alosetron, it might result in 2000 cases of severe constipation. ${ }^{1}$ As quoted by Thomas Permutt of the US Food and Drug Administration, the incidence of severe constipation with alosetron was 11 in some 11000 patients. $^{3}$ The incidence with placebo was three in some 3000 patients-which is also one in 1000-so it cannot be inferred that treatment of 2 million patients would result in 2000 cases.

We need to know the absolute risk increase associated with the use of alosetron. This would lead to the more relevant calculations of the number needed to treat to result in one of the complications associated with alosetron, and the 95\% confidence intervals on those numbers.

The size of the risk associated with alosetron seems to be still unknown. Even the quoted statement by GlaxoSmithKline of a fivefold increase in the risk of developing ischaemic colitis ${ }^{2}$ is not very helpful without the absolute risk, the number needed to treat, and the confidence intervals. Much of the controversy discussed in these articles is meaningless without a better quantitative understanding of the size of the risks involved.

Robert H Palmer medical director

Forest Laboratories, 909 Third Avenue, New York

NY 10022, USA

robert.palmer@frx.com
1 Lièvre M. Alosetron for irritable bowel syndrome. BM] or a victory for patients' rights? BMJ 2002;325:592. (1 September.)

3 Gastrointestinal Drugs Advisory Committee and Dru Safety and Risk Management Subcommittee of the Advisory Committee for Pharmaceutical Science, April 23, 2002. www.fda.gov/ohrms/dockets/ac/02/transcripts 3848T1.pdf (accessed 26 Nov 2002).

\section{Preventing stroke with ramipril-authors' reply}

EDITOR-Our publication of the effects of ramipril on stroke should be taken in the context of the main publication that described the effects on a number of major clinical outcomes and provides the necessary information to calculate the number needed to treat. ${ }^{12}$ When one considers all major vascular events prevented, the number needed to treat with ramipril to prevent one event is extremely small (table)

The side effects of ramipril are described in our main paper, and none of them offset the clinical benefits. Parmar's cost effectiveness analysis is incorrect as it does not take into account the prevention of vascular events and related hospitalisation. ${ }^{3}$ In a formal cost effectiveness analysis, the use of ramipril for five years is cost neutral. ${ }^{4}$

Yudkin speculates whether the benefits in the HOPE study can be achieved with other blood pressure lowering agents. ${ }^{3}$ This is not known. The HOPE results are supported by the heart failure trials in normotensive individuals and in two trials. Ramipril was superior to amlodipine in reducing mortality despite similar blood pressure lowering in the recent African American study of kidney disease and hypertension (AASK). ${ }^{5}$ The losartan intervention for endpoint reduction (LIFE) study showed that in people who have hypertension and left ventricular hypertrophy, losartan, an angiotensin-2 receptor blocker, significantly reduced major vascular events by $13 \%$ compared with atenolol, despite achieving similar blood pressure lowering. ${ }^{6}$ These data indicate that drugs that block the renin-angiotensin system have benefits beyond blood pressure lowering in people at high risk. 2002;325:555. (14 September.)

2 Moynihan R. Alosetron: a case study in regulatory capture

Salim Yusuf director yusufs@mcmaster.ca

Jackie Bosch assistant clinical professor Population Health Research Institute, McMaster University, 237 Barton Street East, Hamilton, ON, Canada L8L 2X2

Peter Sleight professor emeritus of cardiovascular medicine

John Radcliffe Hospital, University of Oxford, Oxford OX3 9DU

1 Bosch J, Yusuf S, Pogue J, Sleight P, Lonn E, Rangoonwala $\mathrm{B}$, et al. Use of ramipril in preventing stroke: double blind randomised trial. BMJ 2002;324:699.

2 The Heart Outcomes Prevention Evaluation (HOPE) Study Investigators. Effects of an angiotensin-convertingenzyme inhibitor, ramipril, on cardiovascular events in high-risk patients. N Engl J Med 2000;342:145-53.

3 Correspondence. Preventing stroke with ramipril. BMJ 2002;325:439. (24 August.)

4 Lamy A, Yusuf S, Pogue J, Gafni A, on behalf of the HOPE investigators. The economic implications of the use of ramipril in high risk patients based upon the HOPE study. Circulation (in press).

5 Agodoa LY, Appel L, Bakris GL, Beck G, Bourgoignie J, Briggs JP, et al, for the African American study of kidney disease and hypertension. Effect of ramipril versus amlodipine on renal outcomes in hypertensive nephrosclerosis: a randomized controlled trial. JAMA 2001:285:2719-28.

6 Lindholm LH, Ibsen H, Dahlof B, Devereux RB, Beevers

Ling $G$, de Faire U, et al, for the LIFE Study Group. Cardiovascular the losartan intervention for endpoint reduction in hypertension study (LIFE): a randomized trial against atenolo.
Lancet 2002; 359:1004-10.

\section{More travel advice and fewer vaccinations are needed}

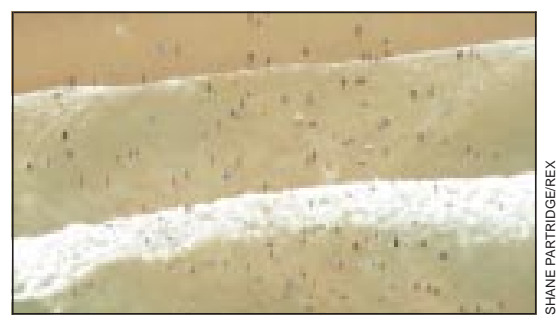

Beaches, bites, bugs, and boils

EDITOR-The health risks associated with international travel range from minor symptoms to severe morbidity and death. In 2000 , residents of the United Kingdom made 56.8 million visits abroad, 3.3 times the number made in 1980 . Of all visits abroad, $72 \%$ were to countries in the European Union and 9\% were to North America

Events prevented per 1000 people treated in the HOPE study

\begin{tabular}{lcc}
\hline No of deaths & $\begin{array}{c}\text { No of events prevented per } \\
\mathbf{1 0 0 0} \text { people treated }\end{array}$ & $\begin{array}{c}\text { Correction for } \mathbf{2 0} \% \\
\text { non-compliance }\end{array}$ \\
\hline Myocardial infarction & 18 & 23 \\
\hline Stroke & 16 & 20 \\
\hline Revascularisation & 9 & 11 \\
\hline Heart failure & 26 & 33 \\
\hline Cardiac arrest & 26 & 33 \\
\hline Diabetes complications & 5 & 6 \\
\hline New diabetes & 12 & 15 \\
\hline Total events prevented (No needed to treat to prevent one event) & 16 & 20 \\
\hline No of people in whom an event is prevented (No needed to treat & $128(8)$ & $161(6)$ \\
\hline to prevent one person developing an event) & $59(17)$ & $74(14)$
\end{tabular}


Hand in hand with an increase in travel we can expect a similar increase in travel related morbidity, and therefore a need for effective, accessible, and appropriate pretravel health advice. We were encouraged by the recognition of travel medicine as an important role of the United Kingdom's public health service. ${ }^{2}$ We were, however, disappointed at the review's emphasis on vaccine preventable disease, including hepatitis A (81 cases in 2000), which from surveillance data provided by the Public Health Laboratory Service shows a fall in cases over the 20 year period. ${ }^{3}$ Likewise, the number of cases of imported malaria has remained static over this time, despite the threefold increase in travel.

The Foreign and Commonwealth Office consular report highlights 1843 deaths in United Kingdom residents abroad during 2001; road traffic accidents, drowning, and suicide were the commonest causes of death after medical causes. ${ }^{4}$ Diarrhoea, although not usually a cause of serious morbidity, affects up to $70 \%$ of tourists on package holidays in tropical counties. ${ }^{5}$

Risk assessment is important to rationalise pre-travel preparation, but the advice needs to reflect the health risk and not the interventions available. The emphasis on vaccination for low risk travel may give a false sense of security and encourage unsafe eating and drinking. Failing to advise on the management of diarrhoea, a much more common event, may lead to dehydration and admission to hospital.

Morbidity associated with behaviourfor example, sexually transmitted disease and solar and skin associated problems, alcohol related traumas, and injuries from recreational activities-makes up the main proportion of illness associated with travel. Prevention of these and the other diseases mentioned above requires effective advice and good communication between travellers and their advisers.

The emphasis on vaccinating travellers rather than advising them is a widely held misconception and needs to be corrected. Health promotion and health education need to be the focus of pre-travel consultations. Risk assessment should be based on a broader view than administering drugs and vaccines.

N Hoveyda specialist registrar in public health medicine

n.hoveyda@doctors.org.uk

Ron Behrens senior lecturer

London School of Hygiene and Tropical Medicine, Department of Infectious and Tropical Diseases, Clinical Research Unit, London WC1E 7HT

1 National Statistics. Travel trends. A report on the 2000 international passenger survey. London: Stationery Office, 2001. www.statistics.gov.uk/downloads/theme_transport/ TTrends2000.pdf (accessed 2 Sep 2002).

2 Zuckerman JN. Travel medicine. BMJ 2002;325:260-4. (3 August.)

3 Public Health Laboratory Service. Hepatitis A laboratory reports, England and Wales, by travel history, 1990-2000. www.phls.co.uk/topics_az/hepatitis_a/data_lab_travel.htm (accessed 10 Dec 2002).

4 Foreign and Commonwealth Office. Consular work annua review 2001. http//files.fco.govuk/consular/ report2001.pdf (accessed 2 Sep 2002).

5 Von Sonnenburg F, Tornieporth N, Waivaki P, Lowe B, Peruski LF Jr, DuPont HL, et al. Risk and aetiology of diarrhoea at various tourist destinations. Lancet rhoea at

\section{Screening populations at low risk carries high risks}

EDIToR-In their key points Lu-Yao et al say that the lack of association between more intensive screening and treatment and lower mortality from prostate cancer means that trials should continue to settle this question. More research is the classic conclusion of all studies, but is it true?

Firstly, trials cannot be used to prove that something does not work. That is unethical; there has to be at least a sound presumption that screening will be effective. It is also futile, as newer screening tests will replace the older ones. The clamour for more testing will only increase.

Secondly, even if screening were effective, could it ever be efficient? The risk of any specific cancer is very low. The absolute risk of death from prostate cancer before the age of 75 was $1.33 \%$ in the Netherlands. ${ }^{3}$ If we assume a risk reduction of $25 \%$ (which would be high), the absolute risk reduction is $0.33 \%$, which means that 300 men need to participate in a population screening programme to save one death.

If we take three to five screening rounds in the programme to obtain this reduction (which would be a small number), in 900-1500 cases participants will be at risk of overdiagnosis and overtreatment-known to cause impotence and incontinence- to save one death.

Cancer screening is based on biased information. Benefit is taken for granted but the risks and perils of screening are not mentioned. A simple calculation can easily be made for all screening procedures: numbers of screening procedures, numbers of diagnostic and therapeutic interventions induced, and numbers of disabilities caused by screening compared to numbers of lives saved. Many people will not believe you, which shows that they understand you all too well.

Part of informed consent is that people should be informed of the true, absolute risks, including risks of overdiagnosis and overtreatment. Cancer risk management should learn from cardiovascular risk management, ${ }^{4}$ where the risks are many times higher but only populations at increased risk are targeted.

Luc Bonneux associate professor

Julius Center for Health Sciences, Utrecht Medical Center, HP D 01.335, PO Box 85500NL-3508 GA Utrecht, Netherlands

l.bonneux@jc.azu.n

1 Lu-Yao G, Albertsen PC, Stanford JL, Stukel TA, Walker-Corkery ES, et al. Natural experiment examining impact of aggressive screening and treatment on prostate cancer mortality in two fixed cohorts from Seattle area and Connecticut. BMJ 2002;325:740. (5 October.)

2 Adami HO, Baron JA, Rothman KJ. Ethics of a prostate Adami HO, Baron JA, Rothman KJ. Ethics of

cancer screening trial. Lancet 1994;343:958-60.
3 Netherlands Cancer Registry. Incidence of cancer in the Netherlands 1997. Amsterdam: Netherlands Cancer Registry, 2001.

4 Jackson R, Barham P, Bills J, Birch T, McLennan L, MacMahon S, et al. Management of raised blood pressure in New Zealand: a discussion document. BMJ 1993:307:107-10.

\section{Embryo selection for complex traits is impracticable}

Editor-With respect to the news item by Hargreaves, ${ }^{1}$ much of the concern about the possibility of "designer babies" is misplaced. The barriers to successful selection of "superior" babies are likely to remain insurmountable, outside the context of selection for babies unaffected by genetic disease (which is generally not controversial).

Traits such as intelligence and aspects of personality are genetically complex. Any one gene is unlikely to be shown to contribute more than a small amount to the variation in these characteristics in the population. To select at pre-implantation diagnosis for high intelligence (for example) with any realistic chance of success, several, perhaps many, genes would probably need to be tested. The problem with this is that each additional gene tested reduces the number of embryos available for implantation.

Suppose that there are three genes of interest, each of which has a favourable allele that confers an advantage in a heterozygous state and that one of the parents carries the advantageous allele for each of the three genes. The chance of an embryo carrying all three favoured alleles is one in eight. Each additional gene in this model halves the number of suitable embryos. But in practice, the availability of embryos for testing at pre-implantation diagnosis is usually quite limited-almost always fewer than 20, and often only a handful. Some embryos will not be suitable for implantation. Also, even if problems such as allele dropout can be eliminated, a selection process that reduces the availability of embryos eightfold (or 16-fold for four alleles, 32-fold for five, and so on) will render the chances of a successful pregnancy very small.

This is a fairly conservative model; if the beneficial allele is recessive and both parents are heterozygous, testing for just one gene will reduce the number of available embryos fourfold.

Designer babies are thus an interesting topic for theoretical debate, but not a practical proposition and not likely to become one.

Edwin P Kirk staff specialist in medical genetics

Sydney Children's Hospital, High Street, Randwick, NSW 2031, Australia

kirked@sesahs.nsw.gov.au

1 Hargreaves S. Safeguards needed now to preven unethical genetic selection in future. BMJ 2002;325:733. (5 October.)

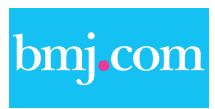

All letters to the editor should be submitted as rapid reponses via bmj.com-for more information, access bmj.com/misc/tips/tip5.shtm/ and bmi.com/advice/sections.shtml\#letters 